\title{
Non-Genetically Improving the Natural Cytotoxicity of Natural Killer (NK) Cells
}

\author{
Martin Villalba ${ }^{1,2 *}$, Catherine Alexia ${ }^{3}$, Anais Bellin-Robert ${ }^{3}$, \\ Alexis Fayd'herbe de Maudave ${ }^{3}$ and Delphine Gitenay ${ }^{3}$ \\ ${ }^{1} I R M B$, Univ Montpellier, INSERM, CHU Montpellier, CNRS, Montpellier, France, ${ }^{2}$ IRMB, CHU Montpellier, Montpellier, \\ France, ${ }^{3}$ IRMB, Univ Montpellier, INSERM, CHU Montpellier, Montpellier, France
}

\section{OPEN ACCESS}

Edited by:

Fabio Malavasi,

University of Turin, Italy

Reviewed by:

Vladimir Jurisic,

University of Kragujevac, Serbia

Pappanaicken R. Kumaresan,

University of Texas MD Anderson

Cancer Center, United States

Massimo Dominici,

University Hospital of Modena, Italy

${ }^{*}$ Correspondence:

Martin Villalba

martin.villalba@inserm.fr

Specialty section:

This article was submitted to

Cancer Immunity and Immunotherapy,

a section of the journal

Frontiers in Immunology

Received: 25 June 2019 Accepted: 10 December 2019

Published: 13 January 2020

Citation:

Villalba M, Alexia C, Bellin-Robert A,

Fayd'herbe de Maudave A and

Gitenay D (2020) Non-Genetically

Improving the Natural Cytotoxicity of

Natural Killer (NK) Cells.

Front. Immunol. 10:3026.

doi: 10.3389/fimmu.2019.03026
The innate lymphocyte lineage natural killer (NK) is now the target of multiple clinical applications, although none has received an agreement from any regulatory agency yet. Transplant of naïve NK cells has not proven efficient enough in the vast majority of clinical trials. Hence, new protocols wish to improve their medical use by producing them from stem cells and/or modifying them by genetic engineering. These techniques have given interesting results but these improvements often hide that natural killers are mainly that: natural. We discuss here different ways to take advantage of NK physiology to improve their clinical activity without the need of additional modifications except for in vitro activation and expansion and allograft in patients. Some of these tactics include combination with monoclonal antibodies (mAb), drugs that change metabolism and engraftment of specific NK subsets with particular activity. Finally, we propose to use specific NK cell subsets found in certain patients that show increase activity against a specific disease, including the use of NK cells derived from patients.

Keywords: NK cells, microenvironment, monoclonal antibodies (mAbs), antibody-dependent cell cytotoxicity (ADCC), autoimmune diseases, CD45RARO

\section{INTRODUCTION}

Innate lymphoid cells (ILCs) play a main role in immune-related disorders and are divided into three groups: ILC1s, ILC2s, and ILC3s (1). Natural killer (NK) cells, which belongs to the ILC1 group, are bone marrow derived cytotoxic lymphocytes (CL) that are well-equipped for the destruction of target cells without the need for prior antigen stimulation. In peripheral blood, human NK cells are mostly $\mathrm{CD} 3^{-} \mathrm{CD} 56^{\mathrm{dim}}$ cells with high cytotoxic activity, while $\mathrm{CD} 3^{-} \mathrm{CD} 56^{\text {brigth }}$ cells excel in cytokine production (2). Additional markers can be used to identify specific subsets within these NK cell populations (2-4). In vitro evidence indicates that CD56 bright $\mathrm{NK}$ cells are precursors of CD56 $6^{\mathrm{dim}} \mathrm{NK}$ cells and this might also be the case in vivo (3). In contrast to T cells, grafted NK cells show short live, low expansion and low alloreactivity such as graft-versus-host (GVH) in humans. Hence, NK can provide a potential source of allogeneic "off-the-shelf" cellular therapy and mediate major anti-target effects without inducing potentially lethal alloreactivity. Given the multiple unique advantages of NK cells, researchers are now exploring different ways to expand and/or activate them for clinical purposes. 


\section{NK CELLS IN CLINICS: THE PROBLEMS}

Researchers working on the clinical use of NK cells have found numerous challenges. First, this cell lineage represents a low percentage of lymphocytes, usually estimated to $5-15 \%$. In addition this changes during human development (4), making the transfer of sufficient allogeneic cells from a single donor to a patient challenging.

Second, NK cells have low lifespans, in average 1 week (5), suggesting that allogenic cells will shortly survive after engraftment. However, these results should be taken with caution. Lifetime studies were performed using deuterium incorporation, and only actively dividing cells incorporate it. Hence, this technique may not account for long-lived, non-dividing cells. Moreover, researchers normally focus on peripheral blood, hence NK cells mainly homing in lymph nodes such as CD56 ${ }^{\text {bright }}$ cells are not taken into account in their real weight (5). But, studies in blood are valid considering that allogeneic NK cells for engraftment are obtained from peripheral blood. Moreover, in vitro stimulated NK cells normally gain a mature phenotype despite high CD56 expression (6). Therefore, the previous estimates are a reasonable proxy for the amount of time NK cells will be active after allogenic engraftment. In agreement, the persistence of ex vivo haploidentical IL-2activated and -expanded NK cells ranges between 7 and 10 days in patients with AML, NHL, and ovarian cancer (7).

The third challenge is that NK cells show doubling times of 1.25 days after activation (8). This is significantly longer than $\mathrm{T}$ cell doubling time during the initial expansion phase, which are 8 and $11 \mathrm{~h}$ for $\mathrm{CD}^{+}{ }^{+}$and $\mathrm{CD} 4^{+} \mathrm{T}$ cells, respectively (9). Moreover, after allogeneic engraftment most clinical results failed to show significant expansion of donor NK cells $(6,7,10-13)$. Perhaps the high renew and short lifespan account for these poor in vivo expansions because NK cells have already strongly expanded during their maturation and they are prone to "effector-like" phenotype, at least in the blood population.

Fourth, naïve NK cells possess a relatively low activity compare to activated cells $(6,14)$. This could be responsible of the low efficacy of NK cell-mediated therapies (11-13).

Fifth, there are several attempts to activate endogenous NK cells, e.g., by blocking NK cell inhibitory receptors. This led to the development of IPH2101, a killer inhibitory receptors (KIRs)/KIRL blocking antibody ( $\mathrm{Ab})$ (15), or monalizumab, a humanized anti-NKG2A Ab (16). This approach has the inconvenience that in cancer patients NK cells are hyporeactive $(11,12,17)$. Moreover, new therapies such as NK cell-based therapies are usually tested on patients with advance clinical

\footnotetext{
Abbreviations: ADCC, antibody-dependent cell-mediated cytotoxicity; AML, acute myeloid leukemia; B-CLL, B-cell chronic lymphocytic leukemia; B-NHL, B-cell non-Hodgkin's lymphoma; BCL, B-cell lymphoma; DLBCL, Diffuse large Bcell lymphoma; EBV, Epstein-Barr virus; EGFR, epidermal growth factor receptor; e-NK, expanded NK cells; FL, follicular lymphoma; GMP, good manufacturing practices; GvHD, graft-versus-host disease; HSCT, hematopoietic stem cell transplantation; LEN, lenalidomide; mAbs, monoclonal antibodies; NCRs, natural cytotoxicity receptors; NK cells, natural killer cells; OBZ, obinutuzumab; PFS, progression-free survival; RTX, rituximab; UCB, umbilical cord blood; UCBT, umbilical cord blood transplantation.
}

stages, which correlate with enhance NK cell dysfunction, at least in multiple myeloma (18). This suggests that endogenous NK could be unable to eliminate tumor cells even after releasing KIR inhibition. Interestingly, recent clinical data also in myeloma suggest that such antibodies can modify the endogenous NK repertoire and make them further hyporeactive (19). Other clinical attempts to activate endogenous NK cells include the use of lenalidomide [LEN; $(20,21)$ ]. Biological results from the Phase Ib/II clinical trial GALEN suggest that LEN could facilitate obinutuzumab (OBZ)-mediated NK cell activation (21), as was observed with rituximab (RTX) (22). In fact cancer patients, at least those with hematological cancers, already possess NK cells, which recognize and kill tumor cells, but are unable to control the disease $(21,23,24)$. Why only a fraction of NK cells is fighting against the tumor is unknown. Which is known is that blood-born cancer cells use different mechanisms for immune escape $(25,26)$, e.g., by inducing NK cell dysfunction (27). This mechanism has also been observed in a variety of solid tumor patients (17).

Due to all these adverse points recent clinical approaches target in vitro expanded and activated NK cells and hence the use of allogeneic NK cells.

\section{MECHANISMS OF NK CELL EXPANSION}

In this context, clinical-grade production of allogeneic NK cells is efficient (28) and NK cell-mediated therapy, including the use of in vitro expanded allogeneic NK cells, seems safe (11, 13, 28-31). This review does not focus on NK cell expansion, but in how we can "naturally" increase NK activity. There are recent reviews regarding NK cell expansion, e.x. (32).

But, it is important to note that choosing the correct donor can improve the killing activity of NK cells. There are different possibilities to choose the "best" donor including selection od donors with HLA/KIR mismatch with the patient (33), donors with a group B KIR haplotype (these donors have 1 or more of the B-specific genes: KIR2DS1, 2, 3, 5, KIR2DL2, and KIR2DL5) (34) or even donors with KIR2DS2 ${ }^{+}$immunogenotype (35).

New attempts try developing disease-specific cytokine cocktails to activate in vitro patient NK cells (36-38). This is pertinent because in vitro the effects of these cocktails are different between patients and healthy donors. (39). However, despite the strong cytolytic potential of expanded NK cells against different tumors in vitro, clinical results have been very limited (11-13), e.g., NK are considered highly cytotoxic against AML tumor cells, but their efficacy as monotherapy in the clinic is low (11-13). Moreover, the results using NK cell therapy in animal models of solid tumors or in clinical trials are disappointing, even if NK cells can eliminate the engrafted cell type or the primary tumor cells in vitro (11-13). In this context, it should be noted that different culture media affect tumor recognition by NK cells (40). In summary, there is not any expansion protocol that produces allogeneic NK cells able to efficiently eliminate solid tumor cells in vivo. Why NK cells destroy most targets in vitro but not in vivo is unknown. Tumor cells strongly modify the expression of ligands, which are 
recognized by NK cell activating or inhibiting receptors when cultured in vitro (40). This could lead to the mistrust that those specific tumor cells would be NK sensitive or resistant in vivo. Allogeneic NK cells survive for several days in patient's body (see above), hence their initial survival is probably not the blocking step for their efficacy in vivo. Impaired tumor infiltration and/or low cytolytic activity in the immunosuppressive tumor environment are usually pointed out as responsible of their low function in vivo. Hence, researchers have focused on protocols to activate them enough to bypass these clinical obstacles.

There are many protocols to expand and activate in vitro NK cells $(6,11,13,28-31)$. For many clinical uses, the manufactured cells should express the Fc $\gamma$ RIIIa, also called CD16. The probably exception is those protocols wishing to generate chimeric antigen receptor (CAR) NK. We have produced umbilical cord blood (UCB)-derived NK cells because they are rapidly available, present low risk of viral transmission and have less strict requirements for HLA matching and lower risk of $\mathrm{GvH}$ disease (GvHD) (11). Expansion was driven by Epstein-Barr virus (EBV)-transformed lymphoblastoid B cell lines as accessory cells, which induce a unique NK cell genetic reprogramming (14), generating effectors that overcome the anti-apoptotic mechanism of leukemic cells (41) and that are able to eliminate tumor cells from patients with poor prognosis (42). NK cells obtained with this protocol perform antibody-dependent cell cytotoxicity (ADCC) in vitro and in vivo with different therapeutic antibodies and against diverse target cells (6).

NK cell expansion is extremely challenging from an industrial point of view $(43,44)$, partly due to the problems described in the previous section. In addition, NK cell production should be easily scaled up and developed with good manufacturing practices (GMP). Several biotech companies are now producing NK cell-based products that could reach the clinic in the future (44). We will discuss now mechanisms to naturally improve NK cytotoxicity. We will not discuss about lymphodepleting chemotherapy, e.g., cyclophosphamide followed by daily fludarabine, which is already largely use in clinics prior to NK cell infusion (45).

\section{CYTOKINES MEDIATE NK ACTIVATION}

Generally, when NK will reach the target microenvironment they will receive a burst of cytokines from other cells, e.g., those immune cells that have already infiltrated the tumor. These cytokines affect NK cell behavior and activation and has extensively been reviewed elsewhere (46). Hence, we will only briefly describe some few uses. IL-2 and IL-15 are strong NK cell activators, but their clinical use in vivo is challenging due to their toxicity (44). Moreover, IL-2 expands and mobilizes regulatory T cells, which dampen the activity of several effector cells including NK (44). IL-15, although less toxic than IL-2, is limited by its short half-life leading to poor functional activity in vivo. However, in vitro both cytokines are very efficient stimuli to activate and expand NK cells $(6,14)$. In fact, membrane-bound IL-15 is currently the best activating cytokine (47), although membrane-bound IL-21 is becoming an interesting challenger $(48,49)$. In any case, long-term cytokine treatment can lead to NK cell exhaustion, which will inhibit NK activity (50).

\section{MODIFYING THE TARGET MICROENVIRONMENT}

Tumor cells, directly or by controlling non-transformed cells, modify the environment to make it immunosuppressive and avoid destruction by effector immune cells $(25,26,50)$. We will discuss here some approaches that can reverse this "negative" microenvironment. We will not discuss drugs that per se sensitize target cells to NK cells. Tumor-induced modifications include metabolic changes with the production of metabolites that negatively affect NK cell cytotoxicity, e.g., lactate $(26,50)$. This is the classical metabolite produced by tumor cells under the Warburg effect: cells perform glycolysis even in the presence of ample oxygen (26). To recover the reducing power of $\mathrm{NAD}^{+}$, which has been reduced to $\mathrm{NADH}^{+}-\mathrm{H}^{+}$during glycolysis, cells reduce pyruvate creating lactate. This mechanism recovers the cell reducing power and allows the glycolysis to proceed. During the Warburg effect, the products that are not oxidized, i.e., that are not consumed to produce $\mathrm{CO}_{2}$, serve to create new intermediate metabolites that are used for anabolism. But in addition, tumor cells release lactate to the external medium. This acidifies the environment and inhibits the antitumor response of CLs because the killing activity of these cells is extremely sensitive to the decrease in $\mathrm{pH}(50,51)$. There are some compounds such as dichloroacetate (DCA) or metformin that inhibit the Warburg effect and block lactate production $(26,52,53)$. It is hence conceivable that such drugs could increase the cytolytic activity of NK, or other CLs, in vivo (Figure 1).

In contrast, during the killing of yeast cells or cryptococcoma, NK cells appeared to profit from the acidic $\mathrm{pH}$ of the microenvironment by displaying enhanced perforin degranulation and killing capacity (51). Therefore, an interesting possibility would be to modify the NK-tumor environment to match that of NK-yeast cells/cryptococcoma in order to increase NK cytotoxicity even at low $\mathrm{pH}$.

Another way to increase NK activity would be to decrease adenosine concentration in tumor environment. This nucleotide is found as much as 100-fold higher in tumors than in normal tissues and contributes to immune evasion by inhibiting for example NK cell cytolytic activity (50). The ectonucleotidases CD39 and CD73 produce large amounts of adenosine, hence their inhibition decreases tumor growth and metastasis. This type of treatment has reached the clinic with the anti-CD73 antibody Oleclumab (50).

Several vitamins, e.g., A, C, and E, induce changes in NK cell markers associated to activation (60). Vitamin A/retinoic acid increases target expression of natural-killer group 2, member D (NKG2D) ligands in mouse, RAE-1 (60), and humans, MICA/B $(61,62)$. However, it can activate $(60,62)$ or inhibit $(14,60,63)$ NK activity depending on the cellular context. Hence, their use in clinics must be carefully studied. 


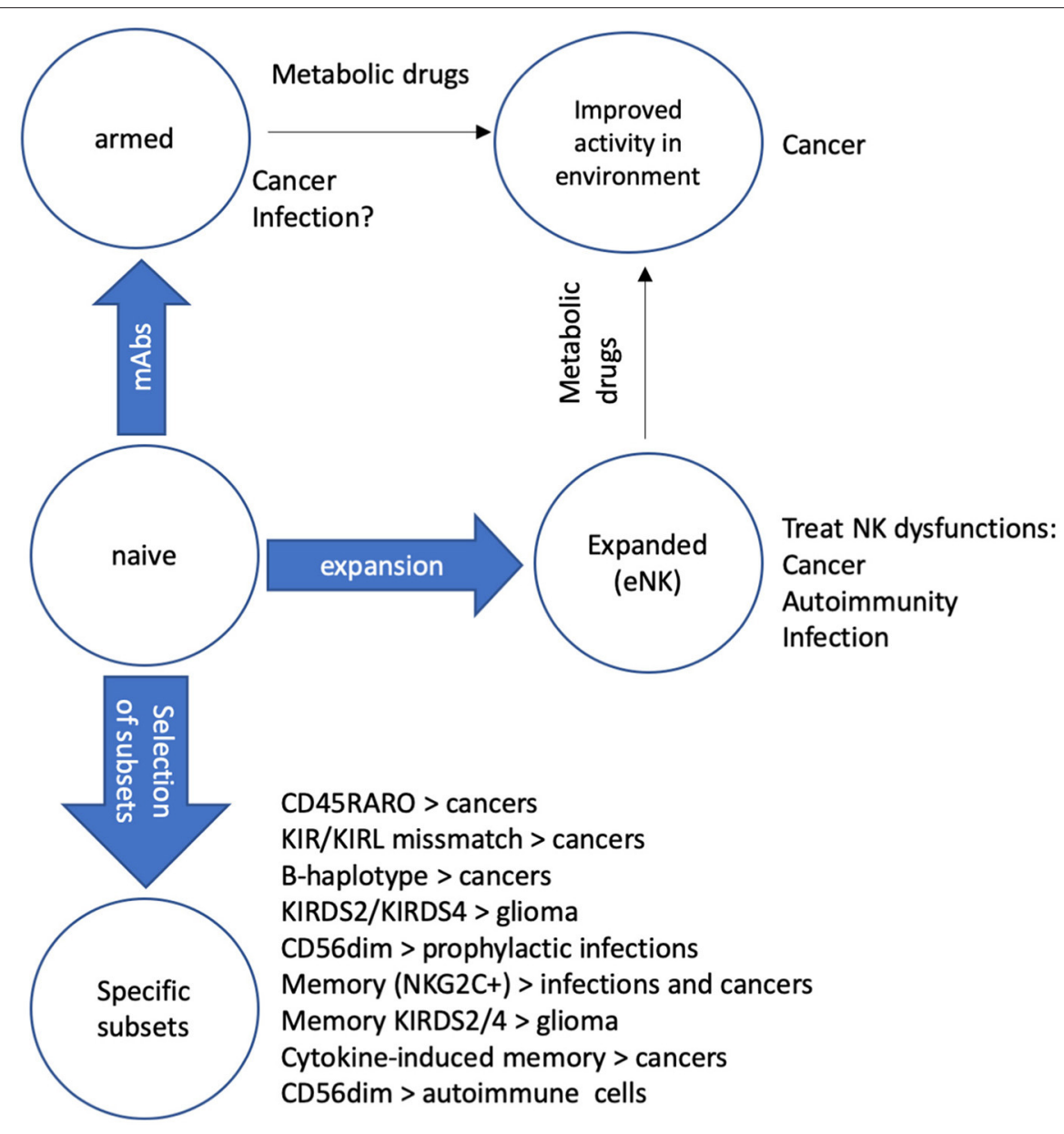

FIGURE 1 | Protocols to recover/improve NK function. We describe several mechanisms to improve NK activity in patients. Naiive NK cells can be "armed" with mAbs that recognize tumor antigens (Ags) to improve their cytolytic activity against cancer cells (6). If specific mAbs against Ags of different pathogens are available, they can be used to arm NK cells to fight infections, mainly in immune compromised patients $(54,55)$. NK cells can be expanded (eNK) to recover NK cell functions in several diseases such as cancer, autoimmune diseases and infections (32). Treatment of patients with metabolic drugs that modify the microenvironment of the target can increase the function of both "armed" NK and eNK $(25,53)$. We also believe that it is possible transfer specific NK cell subsets to treat different diseases such as cancers (11-13), including glioblastoma (56) that has a poor prognosis. Some NK subsets, e.x. memory NK cells could also fight infections (57) when engrafted in patients. Finally, in autoimmune diseases could be clinically relevant to replace immature CD56 bright $\mathrm{NK}$, which are mostly proinflammatory with mature CD56 ${ }^{\text {dim }} \mathrm{NK}$, which eliminate activated immune cells. These two NK subsets differentially express various chemokine receptors, which attract them to distinct organs $(58,59)$. Hence, locally playing with different chemokines should naturally facilitating the recruitment of a specific subset.

\section{ADCC IS NATURAL: NK CELLS AND mAbs}

Cell-mediated immune defense includes ADCC. NK only harbor the activating Fc $\gamma$ receptors CD16a and Fc $\gamma$ RIIc, also known as $\mathrm{CD} 32 \mathrm{c}$. This gives NK a preponderant role in ADCC in humans (64). Although not include in the so-called "natural NK cytotoxicity," ADCC is totally a natural physiological process mediated, at least in large part, by NK cells, but involving coordination and crosstalk of different immune cells (64). Through ADCC NK cells can modulate the adaptive immune response and generate long term protection (65).

Differential response to therapeutic $\mathrm{mAbs}$ has been reported to correlate with a specific polymorphism in CD16 (V158F) (66). This polymorphism is associated with differential affinity for mAbs (64). Indeed $\mathrm{Fc} \gamma \mathrm{Rs}$ variant play an important role in determining prognosis of monoclonal IgG antibodies (mAbs) therapy (67). Hence, an obvious possibility is using NK cell from donors with the $158 \mathrm{~V}$ polymorphism, which shows increase affinity for $\mathrm{Fc}$ and better prognosis to $\mathrm{mAb}$ treatment $(64,67)$. This engrafted NK should show improved activity after transplantation, mainly when associated to $\mathrm{mAb}$ cotherapy. Conversely, different approaches modify the antibody Fc region to increase patient NK cell activity. For example, obinutuzumab, an anti-CD20 $\mathrm{mAb}$, is afucosylated to increase CD16 binding and thereby enhance its ADCC activity (68).

\section{ARMING NK CELLS}

As previously described NK cells recognize antibody-opsonized target cells and hence take advantage of the exquisite selectivity of $\mathrm{mAb}$ to generate a discriminatory immune response against 
target cells. An interesting possibility of increasing NK function is loading $\mathrm{mAbs}$ into the $\mathrm{NK} \mathrm{CD} 16 \mathrm{Fc}$ receptor, giving them an exogenous selectivity against target cells (Figure 1). Recent data show that expanded NK retain RTX on their CD16 at least overnight (6). Moreover, RTX-armed NK show improved cytolytic activity compared to non-armed NK cells. In fact, in vitro results using RTX and $\mathrm{CD}_{2} 0^{+}$tumor cells deerived from chronic lymphocyte leukemia (CLL) patients do not show any differences on NK cell-mediated ADCC between opsonizing targets or "arming" NK (6).

There are other possibilities to "arm" expanded NK cells, e.g., (i) with activating receptors that enhance their natural antitumor capacity; (ii) with chimeric antigen receptors (CAR) that can redirect them toward specific tumor targets (45); or (iii) with death receptor ligands such as a glycosylated form of TNF-related apoptosis-inducing ligand (TRAIL) fusion protein (69). These armed NK cells show improved antitumor function, but these approaches require genetic modification of NK cells, and we do not consider them "natural."

\section{NATURALLY OCCURRING ANTITUMOR NK CELLS: TROGOCYTOSIS AND THE CD45RARO PARADIGM}

The NK cell population with antitumor activity has recently been identified $(21,23,24)$. In multiple hematological cancer patients there is a population of highly activated $\mathrm{CD} 56^{\mathrm{dim}} \mathrm{CD} 16^{+}$ NK cells that have recently degranulated, evidence of killing activity. These cells generally expressed NKp46, NKG2D, and KIRs, whereas expression of NKG2A and CD94 is diminished. They are also characterized by a high metabolic activity and active proliferation. Notably, these NK cells carry, non-NK, tumor cell antigens on their surface, evidence of trogocytosis during tumor cell killing, i.e., they carry CD19 in B cell-derived cancers and CD14 in myeloid-derived cancers $(21,23,24)$. The antitumor NK cells are distinguished by their CD45RA ${ }^{+} \mathrm{RO}^{+}$phenotype, as opposed to non-activated cells in patients or in healthy donors displaying a CD45RA ${ }^{+} \mathrm{RO}^{-}$phenotype $(21,23,24)$. Therefore, antitumor NK cells exist (23). Hence, there is the possibility of selectively expand this population. However, in vitro expansion does not really produce similar phenotypes to those found in cancer patients. Moreover, NK cell markers change in vitro $(23,24)$. Another possibility would be to exchange the antitumor population of two cancer patients. Notably, CD45RARO cells show strong activity against a different tumor cell (23). This is reminiscent with previous in vitro studies showing that $\mathrm{NK}$ cells exhibited enhanced cytotoxicity after a prior co-culture with some tumor cells $(70,71)$. But the in vivo interest of using patient CD45RARO cells to treat other patients goes further that this possible "priming" effect. It is known that tumor cells have been immune sculpted by the host immune system (72). This allows them to immune escape and generate cancers. However, the mechanisms of tumor immune escape are usually different between host/tumor pairs. This suggests that tumors will be better recognized by antitumor NK cells of another patient, supporting the exchange of NK cells between patients (Figure 1).
Obviously, the national health agencies should carefully examine this possibility.

Another possibility is transferring NK cell genotypes that show higher activity against a specific cancer, such as the B-haplotype in AML (34) or KIR2DS2 immunogenotype in glioblastoma (35) (Figure 1).

\section{NK AND INFECTIOUS DISEASES}

In contrast to cancer patients, CD45RARO populations have not been described in patients with viral infections yet $(23,24)$. In view of the safety of allogeneic NK in different tumor treatments described above, their use in infectious diseases is clinically relevant. However, if we usually consider "cancer" as a complex disease, what to say about pathogens so diverse as virus, bacteria, and fungi. Remarkably, a growing body of evidences show that NK cells play a major role in the immunity against all these pathogens, not only by their direct killing of pathogens or infected cells, but also by producing cytokines that activates other immune cells (73). In several pathological conditions leading to immunodeficient patients, allogeneic NK cells could support the recovery of enough protection to decrease infectious complication (54). An example of immunodeficiency occurs during hematopoietic stem cell transplantation (HSCT). The recipient's immune system is usually destroyed with radiation or chemotherapy before the stem cell transfer. Hence, infection is a major complication. Currently, clinicians are trying to use certain immune cell types such as granulocytes or infectiousspecific $\mathrm{T}$ cells to control infection. Although randomized studies failed to demonstrate a significant survival benefit of granulocyte transfusions after HSCT (73). It is known that rapid reconstitution of NK population protects from both infection (54) and tumor relapse $(11,13,73)$. Hence, prophylactic engraftment of NK cells in HSCT patients could protect from infection and decrease relapse, with the advantage that NK cells, and not $\mathrm{T}$ cells, target a broad range of pathogens (Figure 1).

If the use of allogeneic NK cells in patients at risk, i.e., immunocompromised patients as those described above, clinically sounds, this is not the case of immunocompetent individuals. Obviously clinical results of allogeneic NK cell engraftment in these patients are lacking. Despite this, we want to discuss certain medical situations in which it could be useful. Again, with the assumption that the transplant would not be toxic to the patient.

First, the severity of influenza can be associated with transient $\mathrm{T}$ and NK cell deficiency (55) and with specific haplotypes of killer-immunoglobulin-like receptors (KIRs) (74). Engraftment of NK cells from donors with such haplotypes can improve the prognostic of humans that barely respond to influenza vaccine. A similar approach, i.e., engraftment of allogeneic NK cells, could be clinically relevant to treat patients infected with flavivirus, which includes viruses such as West Nile, yellow fever, dengue, Zika, and Chikungunya. Flavivirus-induced diseases are currently generating major health problems and, interestingly, NK cells play a central role in controlling these viruses (75). In other deadly viral infection such as Ebola, which also decreases peripheral NK cell numbers, the transplant of NK cells could 
be inefficient because Ebola virus uses specific NK evasion mechanism (76) and can modulate NK function to increase viral pathogenicity (77). The possible use of virus-specific memory NK cells will be discussed below.

Second, NK cells, through release of perforin and granulysin, kill a variety of bacteria including Mycobacterium tuberculosis, Bacillus anthracis, Escherichia coli, Salmonella typhi, and Trypanosoma congolense $(73,78)$. NK cells can also eliminate host cells infected with intracellular bacterial pathogens by engagement of target cell death receptors, such as Fas- FasL and TNF-related apoptosis-inducing ligand (TRAIL) (73). The transfer of allogeneic, expanded, NK cells in patient infected with those bacteria and with a bad prognostic could have an obvious clinical benefit.

Third, allogeneic NK cells could also be useful for fungal infections of poor prognosis due to their direct effect against a number of pathogenic fungi including mucormycetes, Aspergillus fumigatus, Cryptococcus neoformans, and Candida albicans. In addition, NK cells produce a number of cytokines that activate the antifungal activity of other immune cells (73).

\section{MEMORY NK CELLS}

Viral-infected patients have NK subsets that are associated to antiviral immunity and could be used for clinical purposes. Human cytomegalovirus (HCMV) infection promotes expansion of $\mathrm{NKG}_{2} \mathrm{C}^{+} \mathrm{NK}$ cells with memory-like properties $(79,80)$. Furthermore, NK cells expressing high levels of NKG2C and CD57 are associated with prior HCMV infection. Certain cytokines such as IL-12, which is produced by $\mathrm{CD} 4^{+}$monocytes, are mandatory for $\mathrm{NKG}_{2} \mathrm{C}^{+}$cell expansion (81). However, there is a lack of evidence concerning their specific effect against HCMV itself or if there is a recall response to HCMV reactivation $(82)$.

These HCMV-specific NK cells can originate from CD16induced memory-like $\mathrm{NK}$ cells and hence they can be waked up by HCMV antibodies (57). Once activated, these cells could not only attack HCMV-infected cells, but also other NK cell targets such as transformed cells. Subsequently, they could be transferred to patients lacking them to generate the desired immunity (Figure 1). Direct transfer of anti-HCMV antibodies would probably not work because these antibodies presumably do not mediate in the initial generation of NKG2C + "adaptive" NK cells in HCMV-seronegative individuals (83).

Most glioblastoma express HCMV proteins and HCMV infection imprint NK cells. In addition, KIR2DS2+ and KIR2DS4+ are more potent killers that bulk NK cells in glioblastoma cells (35). Remarkably, CMV impacts disease progression in glioblastoma and the KIR allele KIR2DS4*00101 is an independently prognostic of prolonged survival (56). Hence, the transfer of KIR2DS4*00101 NK cells could specifically improve prognosis of glioma patients.

Another possibility is generating "memory"-like NK cells by incubation with different cytokine cocktails, e.g., IL-2/IL-15/IL$18(57,82)$. Some of these cytokines are already part of the current cocktails to amplify and activate human NK cells in vitro as described earlier. In fact, several of these protocols also used accessory, target, cells to drive NK cell expansion and/or activation. The target cell contact-dependent priming signals to enhance NK cell activation has already been described, although the priming stimulus is unknown (57). This has not stopped their clinical test in clinics (12).

In summary, exploiting NK cells with memory-like properties might increase the efficacy of these cells and help their clinical development. However, it is uncertain if current protocols to produce in vitro expanded NK cells are not really generating "memory-like" NK cells, and hence, the use of "memory-like" NK cell is perhaps already used in clinical studies.

\section{RECOVERING NK ACTIVITY IN AUTOIMMUNE DISEASES BY REPLACING ENDOGENOUS NK CELLS}

NK cells from patients of several autoimmune diseases present populations that can contribute to disease progression. In other cases, endogenous NK cells are defective, e.g., in cytotoxicity, due to genetic or environmental facts. Hence, engrafting NK subsets with proper activity could rescue NK activity and improve prognosis. Below we discuss some specific diseases such as rheumatoid arthritis (RA), multiple sclerosis (MS), and systemic lupus erythematosus (SLE). However, similar approaches could also target type I diabetes (T1D) and Sjögren's syndrome (58).

RA patients accumulate immature NK cells in damaged joints. Sinovial fluid (SF) NK (sfNK) cells derived from these patients are enriched in the $\mathrm{CD} 56^{\text {bright }}$ population (84). Moreover, sfNK produce more IFN $\gamma$ and TNF $\alpha$ after interleukin-15 activation $(84,85)$. IL-15, which is present in the SF of RA patients, correlates with disease severity and is important in disease progression (59). Hence all this may contribute to the production of proinflammatory cytokines and long-term inflammation (58).The sfNK cell subset, high CD56, CD94/NKG2A, CD69, and NKp44 and low CD16, is unlike any population documented in any other organ and is enriched in patients with erosive deformative RA (DRA) $(84,85)$. The percentage of total NK cells was doubled in the peripheral blood and tripled in SF of DRA, as compared to non-deformative RA (NDRA), patients (85). Other characteristics of these sfNK in RA are almost absent KIR expression, low CD57 and high natural killer cell p46-related protein (NKp46) (85). Probably the chemokine receptors specifically expressed by immature NK cells facilitate their infiltration into the damaged joints and favor RA damage exacerbation (85). Interestingly, the sfNK CD56 bright population express CD16, something that is unique, although its functionality was not investigated (85). Since sfNK may play an important role in destruction of joints, which should implicate their IFN $\gamma$ and TNF $\alpha$ production, it would be interesting to replace the immature sfNK with mature CD56 ${ }^{\text {dim }}$ cells (Figure 1). An interesting possibility is using those protocols to produce in vitro expanded NK cells described earlier. Although these NK cells present high CD56 levels, they possess all characteristics of mature and activated NK such as KIR and NKG2D expression [e.g., (6)]. The engraft of these 
cells in damaged joints could reverse the damaging effect of the autologous CD56 $6^{\text {bright }}$ cells.

$\mathrm{MS}$ is an autoimmune inflammatory disease affecting the central nervous system (CNS). Autoreactive CD4 T cells targeting myelin components are critical mediators. NK cells can control inflammation by killing activated, autoimmune, $\mathrm{T}$ cells (58). Activated $\mathrm{T}$ cells increase expression of the death-receptor Fas. In patients in remission, NK highly express Fas ligand (FasL), which can eliminate autoreactive T cells through Fas/FasL interactions (86).

During relapse the FasL ${ }^{\text {high }}$ NK population is lost (86). The site of autoimmunity, i.e., the cerebrospinal fluid, is enriched in immature CD56 bright $\mathrm{NK}$ subset, whereas this population is reduced in peripheral blood (87). Daclizumab, an anti-IL-2R $\alpha$ antibody, ameliorates CNS lesions with a decrease in blood CD4 T cells and increase in blood CD56 $6^{\text {bright }} \mathrm{NK}$ (88). Hence, current knowledge on the biology of MS suggest that engraftment of a mature, cytolytic, $\mathrm{CD} 56^{\mathrm{dim}}$ subset could facilitate elimination of autoreactive T cells (Figure 1). Although a possible negative effect cannot be ruled out due to the presence of NKG2D ligands in oligodendrocytes, astrocytes and microglia (58).

SLE is an autoimmune disorder characterized by production of autoantibodies against DNA and nuclear proteins. Like in RA, there is a polyclonal B-cell activation and expansion. NK cell deficiency correlates with SLE in humans and in mouse models of the disease (58). Again, SLE patients show an increase in the proportion of blood CD56 $6^{\text {bright }} \mathrm{NK}$ cells (89). In addition, NK-dependent cytotoxicity decreases (58). Interestingly in pediatric patients, who show the same NK defects (90), the impaired activity is observed at diagnosis (90). Like in previous described autoimmune diseases reconstitution of a mature $\mathrm{CD} 56^{\mathrm{dim}}$ population in SLE patients could improve their prognosis. These approaches requiring the engraftment of "missing" NK cell subsets need proper allogeneic NK recruitment into the target organ. An obvious solution is local engraftment. Another possibility is using a chemokine cocktail. The two NK cell subsets, i.e., CD56 $6^{\text {bright }}$ and $\mathrm{CD} 56^{\mathrm{dim}}$, differentially express various chemokine receptors, which attract them to distinct organs $(58,59)$. Hence, locally playing with different chemokines should naturally facilitating the recruitment of a specific subset. In anyway, reconstitution of NK cell activity in periphery should improve patient prognosis in these diseases heavily dependent on NK cell function.

\section{NK CELL LINES: ARE THEY NATURAL?}

The difficulties for purify, isolate, expand, and transduce primary NK cells for therapeutic applications led researchers to also focus on NK-cell lines such as NK-92 (NK-92 ${ }^{\circledR}$ ATCC ${ }^{\circledR}$ CRL-2407 ${ }^{\text {TM }}$ and NK-92 ${ }^{\circledR}$ MI ATCC ${ }^{\circledR}$ CRL-2408 $\left.{ }^{\mathrm{TM}}\right)$. There are other NK

\section{REFERENCES}

1. Dzopalić T, Božić-Nedeljković B, Jurišić V. Function of innate lymphoid cells in the immune-related disorders. Hum Cell. (2019) 32:231-9. doi: $10.1007 /$ s13577-019-00257-1 cell lines, but their antitumor cytotoxicity is questioned (91). In any case, our discussion here on NK-92 cells should be valid for new NK cell lines that could reach the clinic. NK-92 phenotype is $\mathrm{CD}^{-}{ }^{-} \mathrm{CD} 56^{+} \mathrm{CD} 16^{-}$and display cytotoxicity against a wide range of human primary leukemias, e.g., B-ALL and CML and leukemic cell lines in vitro and in SCID mouse models (92). Stable expression of mouse and human CD16 gives ADCC to NK-92 cells and generates the cell lines NK-92 ${ }^{\mathrm{mCD} 16}$ and NK-92 hCD16, respectively (93). In addition, they are a renewable resource to generate CAR-NK-92 cells. In line with our previous comments we will not discuss about these transduced cells. In contrast, non-modified NK cell lines show therapeutic effect without the need of genetic modifications (91). However, transformed cell lines present worries, such as uncontrolled growth, which require irradiation before infusion into patients. This suppress cell proliferation while, hopefully, maintaining enough cell cytotoxic activity. NK-92 cells have completed phase I trials in cancer patients, e.g., NCT00900809 and NCT00990717. Results show that irradiated NK-92 cells are safe even at very high doses with minimal toxicity in patients with refractory blood cancers (94). In addition, they show clinical benefits with 2 out of 12 patients showing complete response (94).

\section{CONCLUSION}

In a challenging clinical environment with the arrival of "new" cell-therapy products, NK present several advantages and inconveniences. Their clinical improvement by "natural" means that can easily be accepted by natural agencies will greatly favor their use.

\section{AUTHOR CONTRIBUTIONS}

All authors were involved in preparing and writing the manuscript.

\section{FUNDING}

This work was supported by the PRT-K program 2018 (MV; 2018-021); the French Region Occitanie number: ESR_PREMAT000138/Pré-maturation 2018 NKDx; the Investissements d'avenir Grant LabEx MAbImprove: ANR-10-LABX-53; and Canceropole GSO Emergence (MV; 2018/2019).

\section{ACKNOWLEDGMENTS}

We acknowledge the imaging facility MRI, member of the National Infrastructure France-BioImaging supported by the French National Research Agency (ANR-10-INBS-04, Investments for the future).

2. Bryceson YT, Chiang SC, Darmanin S, Fauriat C, Schlums H, Theorell J, Wood SM. Molecular mechanisms of natural killer cell activation. J Innate Immun. (2011) 3:216-26. doi: 10.1159/000325265

3. Montaldo E, Del Zotto G, Della Chiesa M, Mingari MC, Moretta A, De Maria A, et al. Human NK cell receptors/markers: a tool to analyze 
NK cell development, subsets and function. Cytom A. (2013) 83:702-13. doi: $10.1002 /$ cyto.a.22302

4. Mahapatra S, Mace EM, Minard CG, Forbes LR, Vargas-Hernandez A, Duryea TK, et al. High-resolution phenotyping identifies NK cell subsets that distinguish healthy children from adults. PLoS ONE. (2017) 12:e0181134. doi: 10.1371/journal.pone. 0181134

5. Strauss-Albee DM, Blish CA. Human NK cell diversity in viral infection: ramifications of ramification. Front Immunol. (2016) 7:66. doi: 10.3389/fimmu.2016.00066

6. Sanchez-Martinez D, Allende-Vega N, Orecchioni S, Talarico G, Cornillon A, Vo DN, et al. Expansion of allogeneic NK cells with efficient antibodydependent cell cytotoxicity against multiple tumor cells. Theranostic. (2018) 8:3856-69. doi: 10.7150/thno.25149

7. Shevtsov M, Multhoff G. Immunological and translational aspects of NK cell-based antitumor immunotherapies. Front Immunol. (2016) 7:492. doi: 10.3389/fimmu.2016.00492

8. Liu Y, Wu H-W, Sheard MA, Sposto R, Somanchi SS, Cooper LJN, et al. Growth and activation of natural killer cells ex vivo from children with neuroblastoma for adoptive cell therapy. Clin Cancer Res. (2013) 19:2132-43. doi: 10.1158/1078-0432.CCR-12-1243

9. De Boer RJ, Homann D, Perelson AS. Different dynamics of CD4+ and $\mathrm{CD} 8+\mathrm{T}$ cell responses during and after acute lymphocytic choriomeningitis virus infection. J Immunol Baltim Md. (2003) 171:3928-35. doi: 10.4049/jimmunol.171.8.3928

10. Anel A, Aguilo JI, Catalan E, Garaude J, Rathore MG, Pardo J, et al. Protein kinase C- $\theta$ (PKC- $\theta)$ in natural killer cell function and anti-tumor immunity. Front Immunol. (2012) 3:187. doi: 10.3389/fimmu.2012.00187

11. Sarvaria A, Jawdat D, Madrigal JA, Saudemont A. Umbilical cord blood natural killer cells, their characteristics, and potential clinical applications. Front Immunol. (2017) 8:329. doi: 10.3389/fimmu.2017.00329

12. Kottaridis PD, North J, Tsirogianni M, Marden C, Samuel ER, Jide-Banwo S, et al. Two-stage priming of allogeneic natural killer cells for the treatment of patients with acute myeloid leukemia: a phase I trial. PLoS ONE. (2015) 10:e0123416. doi: 10.1371/journal.pone.0123416

13. Moretta L, Pietra G, Vacca P, Pende D, Moretta F, Bertaina A, et al. Human NK cells: from surface receptors to clinical applications. Immunol Lett. (2016) 178:15-9. doi: 10.1016/j.imlet.2016.05.007

14. Sanchez-Martinez D, Krzywinska E, Rathore MG, Saumet A, Cornillon A, Lopez-Royuela N, et al. All-trans retinoic acid (ATRA) induces miR-23a expression, decreases CTSC expression and granzyme B activity leading to impaired NK cell cytotoxicity. Int J Biochem Cell Biol. (2014) 49:42-52. doi: 10.1016/j.biocel.2014.01.003

15. Vey N, Bourhis JH, Boissel N, Bordessoule D, Prebet T, Charbonnier A, et al. A phase 1 trial of the anti-inhibitory KIR mAb IPH2101 for AML in complete remission. Blood. (2012) 120:4317-23. doi: 10.1182/blood-2012-06-437558

16. André P, Denis C, Soulas C, Bourbon-Caillet C, Lopez J, Arnoux T, et al. Anti-NKG2A mAb is a checkpoint inhibitor that promotes anti-tumor immunity by unleashing both T and NK cells. Cell. (2018) 175:1731-43.e13. doi: 10.1016/j.cell.2018.10.014

17. Hu Z. Overcome the impairment of NK cells for icon and antibody immunotherapy of cancer. J Immune Based Ther Vaccines Antimicrob. (2013) 2:1-8. doi: 10.4236/jibtva.2013.21001

18. Jurisic V, Srdic T, Konjevic G, Markovic O, Colovic M. Clinical stage-depending decrease of NK cell activity in multiple myeloma patients. Med Oncol Northwood Lond Engl. (2007) 24:312-7. doi: 10.1007/s12032-007-0007-y

19. Carlsten M, Korde N, Kotecha R, Reger R, Bor S, Kazandjian D, et al. Checkpoint inhibition of KIR2D with the monoclonal antibody IPH2101 induces contraction and hyporesponsiveness of NK cells in patients with myeloma. Clin Cancer Res. (2016) 22:5211-22. doi: 10.1158/1078-0432.CCR-16-1108

20. Giuliani M, Janji B, Berchem G. Activation of NK cells and disruption of PD-L1/PD-1 axis: two different ways for lenalidomide to block myeloma progression. Oncotarget. (2017) 8:24031-44. doi: 10.18632/oncotarget.15234

21. Vo DN, Alexia C, Allende-Vega N, Morschhauser F, Houot R, Menard C, et al. NK cell activation and recovery of NK cell subsets in lymphoma patients after obinutuzumab and lenalidomide treatment. Oncoimmunology. (2018) 7:e1409322. doi: 10.1080/2162402X.2017.1409322
22. Lagrue K, Carisey A, Morgan DJ, Chopra R, Davis DM. Lenalidomide augments actin remodeling and lowers NK-cell activation thresholds. Blood. (2015) 126:50-60. doi: 10.1182/blood-2015-01-625004

23. Krzywinska E, Allende-Vega N, Cornillon A, Vo DN, Cayrefourcq L, Panabieres C, et al. Identification of anti-tumor cells carrying natural killer (NK) cell antigens in patients with hematological cancers. EBioMedicine. (2015) 2:1364-76. doi: 10.1016/j.ebiom.2015.08.021

24. Krzywinska E, Cornillon A, Allende-Vega N, Vo DN, Rene C, Lu ZY, et al. CD45 isoform profile identifies natural killer (NK) subsets with differential activity. PLoS ONE. (2016) 11:e0150434. doi: 10.1371/journal.pone.01 50434

25. Villalba M, Lopez-Royuela N, Krzywinska E, Rathore MG, Hipskind RA, Haouas $\mathrm{H}$, et al. Chemical metabolic inhibitors for the treatment of blood-borne cancers. Anticancer Agents Med Chem. (2014) 14:223-32. doi: $10.2174 / 18715206113136660374$

26. Villalba M, Rathore MG, Lopez-Royuela N, Krzywinska E, Garaude J, AllendeVega N. From tumor cell metabolism to tumor immune escape. Int J Biochem Cell Biol. (2013) 45:106-13. doi: 10.1016/j.biocel.2012.04.024

27. Baier C, Fino A, Sanchez C, Farnault L, Rihet P, Kahn-Perles B, et al. Natural killer cells modulation in hematological malignancies. Front Immunol. (2013) 4:459. doi: 10.3389/fimmu.2013.00459

28. McKenna DH, Sumstad D, Bostrom N, Kadidlo DM, Fautsch S, McNearney $\mathrm{S}$, et al. Good manufacturing practices production of natural killer cells for immunotherapy: a six-year single-institution experience. Transfusion. (2007) 47:520-8. doi: 10.1111/j.1537-2995.2006.01145.x

29. Miller JS, Soignier Y, Panoskaltsis-Mortari A, McNearney SA, Yun GH, Fautsch SK, et al. Successful adoptive transfer and in vivo expansion of human haploidentical NK cells in patients with cancer. Blood. (2005) 105:3051-7. doi: 10.1182/blood-2004-07-2974

30. Ruggeri L, Mancusi A, Burchielli E, Aversa F, Martelli MF, Velardi A. Natural killer cell alloreactivity in allogeneic hematopoietic transplantation. Curr Opin Oncol. (2007) 19:142-7. doi: 10.1097/CCO.0b013e3280148a1a

31. Rubnitz JE, Inaba H, Ribeiro RC, Pounds S, Rooney B, Bell T, et al. NKAML: a pilot study to determine the safety and feasibility of haploidentical natural killer cell transplantation in childhood acute myeloid leukemia. J Clin Oncol. (2010) 28:955-9. doi: 10.1200/JCO.2009.24.4590

32. Granzin M, Wagner J, Köhl U, Cerwenka A, Huppert V, Ullrich E. Shaping of natural killer cell antitumor activity by ex vivo cultivation. Front Immunol. (2017) 8:458. doi: 10.3389/fimmu.2017.00458

33. Velardi A. Role of KIRs and KIR ligands in hematopoietic transplantation. Curr Opin Immunol. (2008) 20:581-7. doi: 10.1016/j.coi.2008. 07.004

34. Cooley S, Weisdorf DJ, Guethlein LA, Klein JP, Wang T, Le CT, et al. Donor selection for natural killer cell receptor genes leads to superior survival after unrelated transplantation for acute myelogenous leukemia. Blood. (2010) 116:2411-9. doi: 10.1182/blood-2010-05-283051

35. Gras Navarro A, Kmiecik J, Leiss L, Zelkowski M, Engelsen A, Bruserud O, et al. NK cells with KIR2DS2 immunogenotype have a functional activation advantage to efficiently kill glioblastoma and prolong animal survival. $J$ Immunol. (2014) 193:6192-206. doi: 10.4049/jimmunol.1400859

36. Vuletić AM, Jovanić IP, Jurišić VB, Milovanović ZM, Nikolić SS, Tanić NT, et al. In-vitro activation of natural killer cells from regional lymph nodes of melanoma patients with interleukin-2 and interleukin-15. Melanoma Res. (2015) 25:22-34. doi: 10.1097/CMR.0000000000000126

37. Vuletić A, Jovanić I, Jurišić V, Milovanović Z, Nikolić S, Spurnić I, et al. IL2 and IL-15 induced NKG2D, CD158a and CD158b expression on T, NKTlike and NK cell lymphocyte subsets from regional lymph nodes of melanoma patients. Pathol Oncol Res. (2018). doi: 10.1007/s12253-018-0444-2. [Epub ahead of print].

38. Mirjačić Martinović K, Babović N, Džodić R, Jurišić V, Matković S, Konjević G. Favorable in vitro effects of combined IL-12 and IL-18 treatment on NK cell cytotoxicity and CD25 receptor expression in metastatic melanoma patients. $J$ Transl Med. (2015) 13:120. doi: 10.1186/s12967-015-0479-z

39. Mirjačić Martinović KM, Vuletić AM, Lj Babović N, Džodić RR, Konjević GM, Jurišić VB. Attenuated in vitro effects of IFN- $\alpha$, IL-2 and IL-12 on functional and receptor characteristics of peripheral blood lymphocytes in metastatic melanoma patients. Cytokine. (2017) 96:30-40. doi: 10.1016/j.cyto.2017.02.024 
40. Haspels HN, Rahman MA, Joseph JV, Gras Navarro A, Chekenya M. Glioblastoma stem-like cells are more susceptible than differentiated cells to natural killer cell lysis mediated through killer immunoglobulinlike receptors-human leukocyte antigen ligand mismatch and activation receptor-ligand interactions. Front Immunol. (2018) 9:1345. doi: 10.3389/fimmu.2018.01345

41. Sanchez-Martinez D, Azaceta G, Muntasell A, Aguilo N, Nunez D, Galvez EM, et al. Human NK cells activated by EBV lymphoblastoid cells overcome anti-apoptotic mechanisms of drug resistance in haematological cancer cells. Oncoimmunology. (2015) 4:e991613. doi: 10.4161/2162402X.2014.991613

42. Sanchez-Martinez D, Lanuza PM, Gomez N, Muntasell A, Cisneros E, Moraru $\mathrm{M}$, et al. Activated allogeneic NK cells preferentially kill poor prognosis B-cell chronic lymphocytic leukemia cells. Front Immunol. (2016) 7:454. doi: 10.3389 /fimmu.2016.00454

43. Chabannon C, Mfarrej B, Guia S, Ugolini S, Devillier R, Blaise D, et al. Manufacturing natural killer cells as medicinal products. Front Immunol. (2016) 7:504. doi: 10.3389/fimmu.2016.00504

44. Veluchamy JP, Kok N, van der Vliet HJ, Verheul HMW, de Gruijl TD, Spanholtz J. The rise of allogeneic natural killer cells as a platform for cancer immunotherapy: recent innovations and future developments. Front Immunol. (2017) 8:631. doi: 10.3389/fimmu.2017.00631

45. Shimasaki N, Coustan-Smith E, Kamiya T, Campana D. Expanded and armed natural killer cells for cancer treatment. Cytotherapy. (2016) 18:1422-34. doi: 10.1016/j.jcyt.2016.06.013

46. Wu Y, Tian Z, Wei $\mathrm{H}$. Developmental and functional control of natural killer cells by cytokines. Front Immunol. (2017) 8:930. doi: 10.3389/fimmu.2017.00930

47. Imamura M, Shook D, Kamiya T, Shimasaki N, Chai SMH, Coustan-Smith E, et al. Autonomous growth and increased cytotoxicity of natural killer cells expressing membrane-bound interleukin-15. Blood. (2014) 124:1081-8. doi: 10.1182/blood-2014-02-556837

48. Oyer JL, Pandey V, Igarashi RY, Somanchi SS, Zakari A, Solh M, et al. Natural killer cells stimulated with PM21 particles expand and biodistribute in vivo: clinical implications for cancer treatment. Cytotherapy. (2016) 18:653-63. doi: 10.1016/j.jcyt.2016.02.006

49. Denman CJ, Senyukov VV, Somanchi SS, Phatarpekar PV, Kopp LM, Johnson JL, et al. Membrane-bound IL-21 promotes sustained ex vivo proliferation of human natural killer cells. PLOS ONE. (2012) 7:e30264. doi: 10.1371/journal.pone.0030264

50. Chambers AM, Lupo KB, Matosevic S. Tumor microenvironment-induced immunometabolic reprogramming of natural killer cells. Front Immunol. (2018) 9:2517. doi: 10.3389/fimmu.2018.02517

51. Huber V, Camisaschi C, Berzi A, Ferro S, Lugini L, Triulzi T, et al. Cancer acidity: an ultimate frontier of tumor immune escape and a novel target of immunomodulation. Semin Cancer Biol. (2017) 43:74-89. doi: 10.1016/j.semcancer.2017.03.001

52. Charni S, de Bettignies G, Rathore MG, Aguilo JI, van den Elsen PJ, Haouzi D, et al. Oxidative phosphorylation induces de novo expression of the MHC class I in tumor cells through the ERK5 pathway. J Immunol. (2010) 185:3498-503. doi: 10.4049/jimmunol.1001250

53. Catalán E, Charni S, Jaime P, Aguiló J-I, Enríquez J-A, Naval J, et al. MHC-I modulation due to metabolic changes regulates tumor sensitivity to CTL and NK cells. Oncoimmunology. (2015) 4:e985924. doi: 10.4161/2162402X.2014.985924

54. de Witte MA, Kuball J, Miller JS. NK cells and $\gamma \delta$ T cells for relapse protection after allogeneic hematopoietic cell transplantation (HCT). Curr Stem Cell Rep. (2017) 3:301-11. doi: 10.1007/s40778-017-0106-4

55. Fox A, Le NMH, Horby $\mathrm{P}$, van Doorn HR, Nguyen VT, Nguyen HH, et al. Severe pandemic H1N1 2009 infection is associated with transient NK and $\mathrm{T}$ deficiency and aberrant CD8 responses. PLoS ONE. (2012) 7:e31535. doi: 10.1371/journal.pone.0031535

56. Dominguez-Valentin $M$, Gras Navarro A, Rahman AM, Kumar S, Retière C, Ulvestad E, et al. Identification of a natural killer cell receptor allele that prolongs survival of cytomegalovirus-positive glioblastoma patients. Cancer Res. (2016) 76:5326-36. doi: 10.1158/0008-5472.CAN-16-1162

57. Pahl JHW, Cerwenka A, Ni J. Memory-like NK cells: remembering a previous activation by cytokines and NK cell receptors. Front Immunol. (2018) 9: 2796. doi: 10.3389/fimmu.2018.02796
58. Fogel LA, Yokoyama WM, French AR. Natural killer cells in human autoimmune disorders. Arthritis Res Ther. (2013) 15:216. doi: 10.1186/ar4232

59. Yap H-Y, Tee SZ-Y, Wong MM-T, Chow S-K, Peh S-C, Teow S-Y. Pathogenic role of immune cells in rheumatoid arthritis: implications in clinical treatment and biomarker development. Cells. (2018) 7:161. doi: 10.3390/cells7100161

60. Grudzien M, Rapak A. Effect of natural compounds on NK cell activation. $J$ Immunol Res. (2018) 2018:4868417. doi: 10.1155/2018/4868417

61. Kim CH. Control of innate and adaptive lymphocytes by the RAR-retinoic acid axis. Immune Netw. (2018) 18:e1. doi: 10.4110/in.2018.18.e1

62. Fan X-Y, Wang P-Y, Zhang C, Zhang Y-L, Fu Y, Zhang C, et al. Alltrans retinoic acid enhances cytotoxicity of CIK cells against human lung adenocarcinoma by upregulating MICA and IL-2 secretion. Sci Rep. (2017) 7:16481. doi: 10.1038/s41598-017-16745-Z

63. Oliveira L de M, Teixeira FME, Sato MN. Impact of retinoic acid on immune cells and inflammatory diseases. Mediators Inflamm. (2018) 2018:3067126. doi: 10.1155/2018/3067126

64. Lo Nigro C, Macagno M, Sangiolo D, Bertolaccini L, Aglietta M, Merlano MC. NK-mediated antibody-dependent cell-mediated cytotoxicity in solid tumors: biological evidence and clinical perspectives. Ann Transl Med. (2019) 7:105 doi: 10.21037/atm.2019.01.42

65. Michaud H-A, Eliaou J-F, Lafont V, Bonnefoy N, Gros L. Tumor antigen-targeting monoclonal antibody-based immunotherapy: orchestrating combined strategies for the development of long-term antitumor immunity. Oncoimmunology. (2014) 3:e955684. doi: 10.4161/21624011.2014.955684

66. Cartron G, Dacheux L, Salles G, Solal-Celigny P, Bardos P, Colombat P, et al. Therapeutic activity of humanized anti-CD20 monoclonal antibody and polymorphism in IgG Fc receptor FcgammaRIIIa gene. Blood. (2002) 99:754-8. doi: 10.1182/blood.V99.3.754

67. Mellor JD, Brown MP, Irving HR, Zalcberg JR, Dobrovic A. A critical review of the role of FC gamma receptor polymorphisms in the response to monoclonal antibodies in cancer. J Hematol OncolJ Hematol Oncol. (2013) 6:1. doi: 10.1186/1756-8722-6-1

68. Cartron G, Watier H. Obinutuzumab: what is there to learn from clinical trials? Blood. (2017) 130:581-9. doi: 10.1182/blood-2017-03-771832

69. Song X, Hong S-H, Kwon WT, Bailey LM, Basse P, Bartlett DL, et al. Secretory TRAIL-armed natural killer cell-based therapy: in vitro and in vivo colorectal peritoneal carcinomatosis xenograft. Mol Cancer Ther. (2016) 15:1591-601. doi: 10.1158/1535-7163.MCT-15-0937

70. North J, Bakhsh I, Marden C, Pittman H, Addison E, Navarrete C, et al. Tumor-primed human natural killer cells lyse NK-resistant tumor targets: evidence of a two-stage process in resting NK cell activation. J Immunol. (2007) 178:85-94. doi: 10.4049/jimmunol.178.1.85

71. Pal R, Monaghan SA, Hassett AC, Mapara MY, Schafer P, Roodman $\mathrm{GD}$, et al. Immunomodulatory derivatives induce PU.1 down-regulation, myeloid maturation arrest, and neutropenia. Blood. (2010) 115:605-14. doi: 10.1182/blood-2009-05-221077

72. Dunn GP, Bruce AT, Ikeda H, Old LJ, Schreiber RD. Cancer immunoediting: from immunosurveillance to tumor escape. Nat Immunol. (2002) 3:991-8. doi: 10.1038/ni1102-991

73. Schmidt S, Tramsen L, Rais B, Ullrich E, Lehrnbecher T. Natural killer cells as a therapeutic tool for infectious diseases - current status and future perspectives. Oncotarget. (2018) 9:20891-907. doi: 10.18632/oncotarget.25058

74. Aranda-Romo S, Garcia-Sepulveda CA, Comas-García A, Lovato-Salas F, Salgado-Bustamante M, Gómez-Gómez A, et al. Killer-cell immunoglobulinlike receptors (KIR) in severe A (H1N1) 2009 influenza infections. Immunogenetics. (2012) 64:653-62. doi: 10.1007/s00251-012-0623-3

75. Maucourant C, Petitdemange C, Yssel H, Vieillard V. Control of acute arboviral infection by natural killer cells. Viruses. (2019) 11:E131. doi: $10.3390 / \mathrm{v} 11020131$

76. Edri A, Shemesh A, Iraqi M, Matalon O, Brusilovsky M, Hadad U, et al. The ebola-glycoprotein modulates the function of natural killer cells. Front Immunol. (2018) 9:1428. doi: 10.3389/fimmu.2018.01428

77. Fausther-Bovendo H, Qiu X, He S, Bello A, Audet J, Ippolito G, et al. NK cells accumulate in infected tissues and contribute to pathogenicity of ebola virus in mice. J Virol. (2019) 93:e01703-18. doi: 10.1128/JVI.01703-18

78. Onyilagha C, Kuriakose S, Ikeogu N, Kung SKP, Uzonna JE. NK cells are critical for optimal immunity to experimental trypanosoma congolense infection. J Immunol. (2019) 203:964-71. doi: 10.4049/jimmunol.1900103 
79. Lopez-Botet M, Vilches C, Redondo-Pachon D, Muntasell A, Pupuleku A, Yelamos J, et al. Dual role of natural killer cells on graft rejection and control of cytomegalovirus infection in renal transplantation. Front Immunol. (2017) 8:166. doi: 10.3389/fimmu.2017.00166

80. Gumá M, Budt M, Sáez A, Brckalo T, Hengel H, Angulo A, et al. Expansion of CD94/NKG2C + NK cells in response to human cytomegalovirus-infected fibroblasts. Blood. (2006) 107:3624-31. doi: 10.1182/blood-2005-09-3682

81. Rölle A, Pollmann J, Ewen E-M, Le VTK, Halenius A, Hengel H, et al. IL-12producing monocytes and HLA-E control HCMV-driven NKG2C+ NK cell expansion. J Clin Invest. (2014) 124:5305-16. doi: 10.1172/JCI77440

82. Peng H, Tian Z. Natural killer cell memory: progress and implications. Front Immunol. (2017) 8:1143. doi: 10.3389/fimmu.2017.01143

83. Capuano C, Battella S, Pighi C, Franchitti L, Turriziani O, Morrone S, et al. Tumor-targeting anti-CD20 antibodies mediate in vitro expansion of memory natural killer cells: impact of CD16 affinity ligation conditions and in vivo priming. Front Immunol. (2018) 9:1031. doi: 10.3389/fimmu.2018.01031

84. Dalbeth N, Callan MFC. A subset of natural killer cells is greatly expanded within inflamed joints. Arthritis Rheum. (2002) 46:1763-72. doi: 10.1002/art.10410

85. Yamin R, Berhani O, Peleg H, Aamar S, Stein N, Gamliel M, et al. High percentages and activity of synovial fluid NK cells present in patients with advanced stage active Rheumatoid Arthritis. Sci Rep. (2019) 9:1351. doi: 10.1038/s41598-018-37448-z

86. Takahashi K, Miyake S, Kondo T, Terao K, Hatakenaka M, Hashimoto S, et al. Natural killer type 2 bias in remission of multiple sclerosis. J Clin Invest. (2001) 107:R23-9. doi: 10.1172/JCI11819

87. Hamann I, Dörr J, Glumm R, Chanvillard C, Janssen A, Millward JM, et al. Characterization of natural killer cells in paired CSF and blood samples during neuroinflammation. J Neuroimmunol. (2013) 254:165-9. doi: 10.1016/j.jneuroim.2012.08.009

88. Bielekova B, Catalfamo M, Reichert-Scrivner S, Packer A, Cerna M, Waldmann TA, et al. Regulatory CD56 ${ }^{\text {bright }}$ natural killer cells mediate immunomodulatory effects of IL-2R $\alpha$-targeted therapy (daclizumab) in multiple sclerosis. Proc Natl Acad Sci USA. (2006) 103:5941-6. doi: $10.1073 /$ pnas.0601335103
89. Schepis D, Gunnarsson I, Eloranta M-L, Lampa J, Jacobson SH, Kärre $\mathrm{K}$, et al. Increased proportion of CD56bright natural killer cells in active and inactive systemic lupus erythematosus. Immunology. (2009) 126:140-6. doi: 10.1111/j.1365-2567.2008.02887.x

90. Yabuhara A, Yang FC, Nakazawa T, Iwasaki Y, Mori T, Koike K, et al. A killing defect of natural killer cells as an underlying immunologic abnormality in childhood systemic lupus erythematosus. J Rheumatol. (1996) 23:171-7.

91. Klingemann H, Boissel L, Toneguzzo F. Natural killer cells for immunotherapy - advantages of the NK-92 cell line over blood NK cells. Front Immunol. (2016) 7:91. doi: 10.3389/fimmu.2016.00091

92. Yan Y, Steinherz P, Klingemann HG, Dennig D, Childs BH, McGuirk J, et al. Antileukemia activity of a natural killer cell line against human leukemias. Clin Cancer Res. (1998) 4:2859-68.

93. Clémenceau B, Vivien R, Pellat C, Foss M, Thibault G, Vié H. The human natural killer cytotoxic cell line NK-92, once armed with a murine CD16 receptor, represents a convenient cellular tool for the screening of mouse mAbs according to their ADCC potential. mAbs. (2013) 5:587-94. doi: 10.4161/mabs. 25077

94. Williams BA, Law AD, Routy B, denHollander N, Gupta V, Wang X-H, et al. A phase I trial of NK-92 cells for refractory hematological malignancies relapsing after autologous hematopoietic cell transplantation shows safety and evidence of efficacy. Oncotarget. (2017) 8:89256-68. doi: 10.18632/oncotarget.19204

Conflict of Interest: The authors declare that the research was conducted in the absence of any commercial or financial relationships that could be construed as a potential conflict of interest.

Copyright (c) 2020 Villalba, Alexia, Bellin-Robert, Fayd'herbe de Maudave and Gitenay. This is an open-access article distributed under the terms of the Creative Commons Attribution License (CC BY). The use, distribution or reproduction in other forums is permitted, provided the original author(s) and the copyright owner(s) are credited and that the original publication in this journal is cited, in accordance with accepted academic practice. No use, distribution or reproduction is permitted which does not comply with these terms. 